\title{
Intergenerational transmission of psychopathy and mediation via psychosocial risk factors
}

Katherine M. Auty, David P. Farrington and Jeremy W. Coid

\section{Background}

Intergenerational continuities in criminal behaviour have been well documented, but the familial nature of psychopathic personality is less well understood.

\section{Aims}

To establish if there is an association between the psychopathic traits of a community sample of men and their offspring and whether psychosocial risk factors mediate this.

\section{Method}

Participants of the Cambridge Study in Delinquent Development ( $n=478$ dyads) were assessed for psychopathy using the PCL: SV. Multilevel regression models were used to investigate intergenerational continuity and mediation models examined indirect effects.

\section{Results}

The fathers' psychopathy was transmitted to both sons and daughters. The transmission of Factor 1 scores was mediated via the fathers' employment problems. For male offspring, the Factor 2 scores were mediated via the fathers drug use, accommodation and employment problems. For female offspring, Factor 2 scores were mediated via the fathers' employment problems.

\section{Conclusions}

Understanding of the specific role of certain psychosocial risk factors may be useful in developing preventive measures for the development of psychopathy.

\section{Declaration of interest}

None.
Intergenerational continuities in criminal and antisocial behaviour have been demonstrated by several studies, ${ }^{1-3}$ yet the transmission of psychopathic personality traits from parents to their offspring is less well understood. Studies of adults and adolescents suggest that psychopathic traits are moderately heritable, ${ }^{4}$ of early onset ${ }^{5}$ and fairly stable from adolescence through to adulthood. ${ }^{6}$ Parental psychopathy may also have an indirect influence on offspring through environmentally mediated processes such as the family's socioeconomic circumstances or parenting practices. ${ }^{7}$ Although there has been a fair amount of research into the biological and neurocognitive aetiology of psychopathy, ${ }^{8-11}$ psychosocial factors that may influence its development have received far less attention.

Evidence for a relationship between parental and offspring psychopathy is limited. A recent cross-sectional study of a non-referred sample of 83 children found a significant association between maternal affective features of psychopathy and the callous unemotional traits of their children, aged 10 years old. The analysis also suggested that parenting dysfunction fully mediated the relationship. ${ }^{12}$ Studies examining the influence of parental psychopathology on the development of problem behaviour in offspring have traditionally focused on mothers, ${ }^{13}$ but it is also important to understand the role of fathers as men are more likely to have psychopathic traits and engage in persistent antisocial behaviour. ${ }^{14}$ Interest in subthreshold psychopathy has recently been increasing, ${ }^{15,16}$ and studies provide evidence that psychopathy may be a dimensional construct, ${ }^{17}$ often accompanied by less-serious antisocial behaviour. ${ }^{18}$ Although individuals in community samples that meet diagnostic thresholds are a minority, there are often several individuals below them who also experience significant symptoms and impairment. ${ }^{19}$ No large-scale family study has explored the influence of paternal psychopathic traits on offspring psychopathic traits. Therefore, the present research provides a unique opportunity to examine this prospectively in two consecutive generations in a large community sample, and also to examine whether psychosocial risk factors can help explain intergenerational continuities.

\section{Method}

\section{Study design and participants}

The father and offspring dyads are participants in the Cambridge Study in Delinquent Development (CSDD), ${ }^{20}$ a prospective longitudinal study of the development of delinquent behaviour in a community sample of 411 males. The study began in 19612 , with the original cohort containing all boys aged 8 or 9 years old from the registers of six schools in south London.

\section{Procedures}

Between 1984 and 1986, when they were aged 32, 378 of the men (93.80\% of those still alive) participated in a social interview. The social interview asked questions about their accommodation, education, employment, family relationships, parenting, social life, substance misuse, involvement in antisocial behaviour and criminal convictions. They were last contacted in the period 1999 to 2004, then aged approximately 48, for a social interview and health questionnaire; 365 of 394 men who were still alive were interviewed (92.64\%). Of these, $304(83.29 \%)$ also completed the health interview, including the Psychopathy Checklist: Screening Version (PCL: SV) ${ }^{21}$ assessment, which was carried out separately.

Between 2004 and 2013, 550 of their offspring (84.23\%) were also interviewed and assessed for psychopathy. At the time of the interview, their average age was 25.38 (s.d.=3.63). We sought the parents' agreement to the offspring interview, to meet the standards of the South East England Regional Medical Ethics Committee. At each interview, written informed consent was obtained from all participants.

The data from the 550 offspring interviews was then matched with their fathers' data; some of the offspring could not be matched because of the father's death $(n=7)$, the father's refusal $(n=48)$ or the offspring's psychopathy assessment not being completed because the interview was conducted over the telephone $(n=17)$. Therefore, this analysis is based on a sample 
of 478 man and child dyads (243 fathers and sons, and 235 fathers and daughters). The original male participants are referred to as G2 (generation two) and their biological children, G3 (generation three).

\section{Assessment of psychopathy}

Psychopathy was assessed using the PCL: SV. ${ }^{21}$ The evaluation was conducted using information provided by the study participant and behavioural observations made by trained interviewers during a face-to-face interview. Criminal records were obtained for all participants from the Home Office extract of the Police National Computer (PNC) at the Ministry of Justice in London and these provided collateral information. The PCL: SV assessments for the G2 fathers and their G3 offspring were conducted by different researchers during separate phases of the study. The PCL: SV is conceptually and empirically related to its predecessor, the Psychopathy Checklist: Revised (PCL-R), ${ }^{22}$ and is adapted for use with community samples. Its reliability as a measure of psychopathy is reported elsewhere. ${ }^{23}$ In this study interrater reliability was verified after attendance at a training workshop and several sessions where a random sample of 48 participants was rated. The intraclass correlation coefficients (ICC) for Factors 1 and 2 were 0.839 and 0.853 respectively.

\section{Psychosocial risk factors}

Five dichotomous composite psychosocial risk factors were created based on criteria that had previously been used to calculate life success scores for the G2 men at age $32 .{ }^{24}$ These variables were: accommodation problems (two or more of: not a home owner, poor home conditions and more than two addresses in the past 5 years); cohabitation problems (three or more of: not living with a partner, not married or cohabiting for 5 years or more, divorced in the past 5 years and not getting on well with his partner); employment problems (three or more of: currently unemployed, low occupational class, low wages and unemployed for more than 9 months in the past 5 years); alcohol misuse (three or more of: driving while under the influence of alcohol, a heavy drinker, a binge drinker and a $\mathrm{CAGE}^{25}$ score of two or more); drug use (any illegal drug in the past 5 years). Two additional risk factors were created using data from the G2 fathers' interview at age 32: teenage father (at the birth of first child); large family (father living with four or more children). Finally, three risk factors were created using data from the offspring interview: disrupted family (father left the family home before the child's sixteenth birthday); poor supervision (parents never knew where their child was going when they went out before age 16); harsh discipline (parents hit their children with an implement as a form of discipline). The selection of psychosocial risk factors was based on previous CSDD analyses conducted on the G2 males that found these factors to be important predictors of delinquency; ${ }^{26}$ antisocial personality at age $32 ; ;^{27}$ and PCL: SV scores at age $48 .^{28}$

\section{Statistical analyses}

The three relationships in Fig. 1 were modelled using the random effects generalised least squares (GLS) regression XTREG routine or logistic regression XTLOGIT routine in Stata version 12.1 statistical software for Windows. Estimates are based on robust standard errors, which take into account the non-independence of children from the same family.

Statistical mediation analysis ${ }^{29,30}$ was used to determine whether any of the psychosocial risk factors could help explain intergenerational continuities in psychopathy. Only psychosocial risk factors that demonstrated significant relationships for both paths $a$ and $b$ were tested as potential mediators (Fig. 1). The

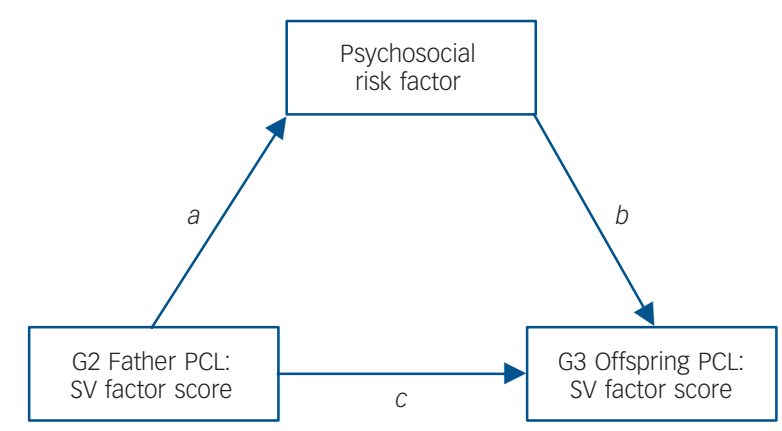

Fig. 1 Mediation model of the intergenerational transmission of psychopathy via psychosocial risk factors.

G2, Generation two; G3, Generation three; PCL: SV, Psychopathy Checklist: Screening version.

direct and indirect effects were computed using the product of coefficients approach. ${ }^{30}$ A bootstrap approach was used to evaluate the significance of the mediator using the cluster(varname) option with the BOOTMM command. This method calculated bias corrected confidence intervals for the indirect effect. Final models are shown with only significant mediators (where the confidence interval does not contain zero). When more than one psychosocial risk factor met the criteria for possible mediation, a multiple mediator model was used. ${ }^{31}$

\section{Results}

The Factor 1 scores for the G2 males ranged from 0 to 8 (out of a possible maximum of 12), with a mean of 1.17 and a standard deviation of 1.69. The Factor 1 scores for the G3 male offspring ranged from 0 to 10 , with a mean of 1.92 and a standard deviation of 2.11. The Factor 1 scores of the G3 female offspring ranged from 0 to 9 , with a mean of 0.95 and a standard deviation of 1.59. The Factor 2 scores for the G2 males ranged from 0 to 11 (out of a possible maximum of 12), with a mean of 2.45 and a standard deviation of 2.76. The Factor 2 scores for the G3 male offspring ranged from 0 to 10 , with a mean of 2.53 and a standard deviation of 2.34. The Factor 2 scores of the G3 female offspring ranged from 0 to 9 , with a mean of 1.42 and a standard deviation of 1.68 .

\section{Association between paternal and offspring psychopathy}

The parameter estimates for the multilevel random-effects regression models that relate the PCL: SV factor scores of the G2 fathers to those of their male offspring are presented in Table 1. The results indicated that there was evidence of intergenerational transmission for both factors; the fathers' Factor 1 score was significantly associated with their male offspring's Factor 1 score. For every one-unit increase in the fathers' Factor 1 score, the sons' Factor 1 score increased significantly $(b=0.41,95 \% \mathrm{CI}$ $0.24-0.59, P<0.001)$. This was also true for the relationship between the fathers' Factor 2 score and the sons' Factor 2 score $(b=0.30,95 \%$ CI $0.20-0.42, P<0.001)$. The results for female offspring also reveal that the fathers' factor scores were significantly associated with those of their daughters for Factor $1(b=0.15,95 \%$ CI $0.03-0.28, P<0.05)$ and for Factor 2 $(b=0.20,95 \%$ CI $0.11-0.28, P<0.001)$.

\section{Paternal psychopathy and psychosocial risk factors}

Presented in Table 2 are the results of the multilevel logistic regression analyses for the psychosocial risk factors. The fathers' 
Table 1 Parameter estimates of multilevel random-effects regression models relating generation two (G2) Psychopathy Checklist: Screening Version (PCL: SV) factor scores to generation three (G3) PCL: SV factor score of male and female offspring

\begin{tabular}{|cccccc|} 
& \multicolumn{2}{c}{ G3 Males $(n=243)$} & & \multicolumn{2}{c|}{ G3 Females $(n=235)$} \\
\cline { 2 - 3 } \cline { 5 - 6 } & $b$ (s.e.) & $P$ & & $b($ s.e $)$ & $P$ \\
\hline G2 Factor 1 & $0.41(0.09)$ & $<0.001$ & & $0.15(0.07)$ & 0.02 \\
\hline G2 Factor 2 & $0.30(0.06)$ & $<0.001$ & & $0.20(0.04)$ & $<0.001$ \\
\hline
\end{tabular}

high psychopathy score meant that several of the psychosocial risk factors were more likely to be present, although all of the odds ratios were less than 2.00 , so would not conventionally be considered large. ${ }^{32}$ For male offspring the largest odds ratios (ORs) were found relating the fathers' factor scores to his drug use: for Factor 1, OR=1.73, 95\% CI 1.39-2.16, $P<0.001$ and for Factor 2, OR $=1.72,95 \%$ CI 1.46-2.02, $P<0.001$. For female offspring, the largest odds ratios were for the fathers' alcohol misuse: for Factor 1, OR $=1.50,95 \%$ CI 1.26-1.79, $P<0.001$ and for Factor 2, OR $=1.67,95 \%$ CI 1.44-1.93, $P<0.001$.

\section{Psychosocial risk factors and offspring psychopathy}

Prevalences for the psychosocial risk factors in the male and female offspring samples as well as parameter estimates for their relationship with the factor scores of the male and female offspring are shown in Table 3. Many of the psychosocial risk factors were found to have a significant relationship with the factor scores of the G3 offspring, particularly for the male offspring. The fathers' employment problems, his alcohol misuse, a disrupted family and poor supervision all had significant relationships with both factors' scores of male and female offspring.

All psychosocial risk factors that were found to have a significant association with the G2 fathers' PCL: SV factor scores, and in turn also had significant associations with the factor scores of the G3 offspring were taken forward to be investigated as potential mediators in the next analysis.

\section{Mediation analysis}

The mediation of the effect of the fathers' factor scores on their offspring's factor scores are shown in Tables 4 and 5 for male and female offspring, respectively. The age of the G3 participants at the time of the PCL: SV assessment was found to be related to their PCL: SV score, so this variable was included in the mediation models as a control variable. For male offspring (Table 4), the proportion of the total effect of the fathers' Factor 1 score that is mediated is 0.263 , the small indirect effect through the fathers' employment problems was significant. The bootstrap results shown that both the direct and the indirect effects are statistically significant. The effect of the fathers' Factor 2 score is mediated through the fathers' accommodation problems, employment

\begin{tabular}{|c|c|c|c|c|}
\hline \multirow[b]{2}{*}{ Psychosocial risk factors } & \multicolumn{2}{|c|}{ Male offspring, OR $(95 \% \mathrm{Cl})(n=243)$} & \multicolumn{2}{|c|}{ Female offspring, OR $(95 \% \mathrm{Cl})(n=235)$} \\
\hline & G2 Factor 1 & G2 Factor 2 & G2 Factor 1 & G2 Factor 2 \\
\hline Accommodation problems & $1.21 *(1.01-1.45)$ & $1.19 * *(1.06-1.32)$ & $1.28 * *(1.10-1.49)$ & $1.21^{* * *}(1.10-1.34)$ \\
\hline Cohabitation problems & $1.24(0.99-1.54)$ & $1.25^{* *}(1.10-1.43)$ & $1.35^{* * *}(1.15-1.59)$ & $1.51^{* * *}(1.33-1.73)$ \\
\hline Employment problems & $1.67^{* * *}(1.37-2.04)$ & $1.42^{* * *}(1.26-1.61)$ & $1.44^{* * *}(1.23-1.70)$ & $1.27 * * *(1.14-1.41)$ \\
\hline Alcohol misuse & $1.46^{* \star *}(1.22-1.77)$ & $1.50^{* * \star}(1.31-1.71)$ & $1.50^{* * *}(1.26-1.79)$ & $1.67^{* * *}(1.44-1.93)$ \\
\hline Drug use & $1.73^{* * *}(1.39-2.16)$ & $1.72^{* * *}(1.46-2.02)$ & $1.33^{* *}(1.12-1.57)$ & $1.56^{* * *}(1.35-1.79)$ \\
\hline Teenage father & $1.08(0.81-1.44)$ & $1.11(0.95-1.31)$ & $1.11(0.91-1.35)$ & $1.05(0.92-1.20)$ \\
\hline Disrupted family & $1.17(0.97-1.42)$ & $1.19 * *(1.06-1.33)$ & $1.35^{\star \star *}(1.16-1.58)$ & $1.35^{* * *}(1.21-1.50)$ \\
\hline Large family & $1.16(0.87-1.55)$ & $1.08(0.91-1.28)$ & $0.96(0.75-1.23)$ & $0.99(0.85-1.15)$ \\
\hline Poor supervision & $1.43 *(1.05-1.93)$ & $1.17(0.97-1.41)$ & $1.25(0.98-1.59)$ & $1.22 *(1.03-1.44)$ \\
\hline Harsh discipline & $0.89(0.61-1.29)$ & $1.02(0.84-1.23)$ & $1.28 *(1.04-1.57)$ & $1.15(0.99-1.33)$ \\
\hline
\end{tabular}

\begin{tabular}{|c|c|c|c|c|c|c|}
\hline \multirow[b]{2}{*}{ Psychosocial risk factors } & \multicolumn{3}{|c|}{ Male offspring $(n=243)$} & \multicolumn{3}{|c|}{ Female offspring $(n=235)$} \\
\hline & Prevalence, $n(\%)$ & Factor $1, b$ (s.e.) & Factor $2, b$ (s.e.) & Prevalence, $n$ (\%) & Factor $1, b$ (s.e.) & Factor $2, b$ (s.e.) \\
\hline Accommodation problems & $69(28.40)$ & $1.13(0.29)^{\star * *}$ & $1.55(0.33)^{\star \star \star}$ & 89 (38.53) & $0.43(0.25)$ & $0.59(0.25)^{*}$ \\
\hline Cohabitation problems & $32(13.17)$ & $0.63(0.40)$ & $1.17(0.46)^{*}$ & $37(16.02)$ & $0.67(0.33)^{*}$ & $1.20(0.34)^{* * *}$ \\
\hline Employment problems & $50(20.58)$ & $1.51(0.32)^{\star \star \star}$ & $2.01(0.36)^{\star \star \star}$ & $51(22.08)$ & $0.84(0.28)^{* *}$ & $1.03(0.29)^{* * *}$ \\
\hline Alcohol misuse & $92(37.86)$ & $0.76(0.27)^{\star * *}$ & $1.02(0.32)^{\star * *}$ & $98(42.42)$ & $0.63(0.24)^{*}$ & $0.81(0.25)^{\star *}$ \\
\hline Drug use & $35(14.40)$ & $1.33(0.37)^{* * *}$ & $2.16(0.43)^{\star \star *}$ & $34(14.72)$ & $0.50(0.34)$ & $0.70(0.35)^{*}$ \\
\hline Teenage father & $20(8.23)$ & $1.67(0.48)^{\star \star \star}$ & $1.73(0.56)^{* *}$ & $28(11.91)$ & $0.59(0.39)$ & $0.67(0.40)$ \\
\hline Disrupted family & $56(24.03)$ & $0.76(0.32)^{*}$ & $0.74(0.36)^{*}$ & $77(33.77)$ & $0.64(0.22)^{\star *}$ & $0.61(0.24)^{*}$ \\
\hline Large family & $18(7.41)$ & $2.19(0.49)^{\star \star \star \star}$ & $2.00(0.61)^{\star *}$ & $24(10.21)$ & $0.47(0.46)$ & $0.07(0.48)$ \\
\hline Poor supervision & $13(5.35)$ & $3.91(0.55)^{\star \star \star}$ & $4.62(0.60)^{* \star \star}$ & $13(5.53)$ & $1.41(0.42)^{* *}$ & $2.07(0.42)^{\star \star \star *}$ \\
\hline Harsh discipline & $17(7.00)$ & $0.97(0.53)$ & $1.86(0.57)^{\star *}$ & $18(7.66)$ & $0.41(0.39)$ & $1.62(0.39)^{* * *}$ \\
\hline
\end{tabular}


Table 4 Mediation of the effect of the fathers' Psychopathy Checklist: Screening Version (PCL: SV) factor scores on their male offspring'S PCL: SV factor score thorough psychosocial risk factors, controlling for age of offspring at assessment

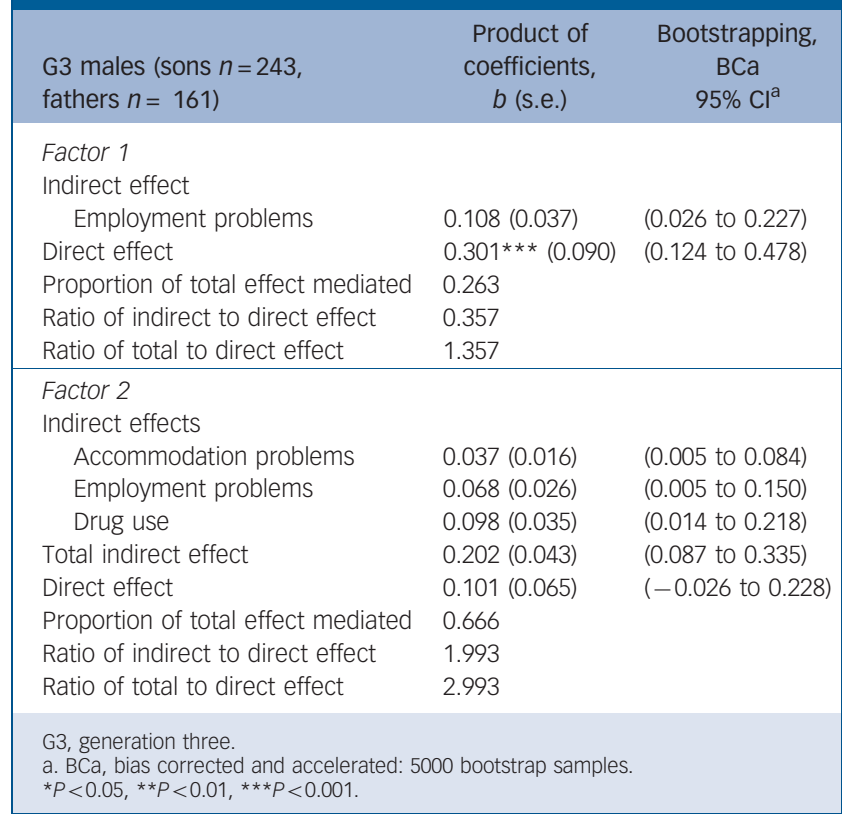

Table 5 Mediation of the effect of the fathers' Psychopathy Checklist: Screening Version (PCL: SV) factor scores on their female offspring'S PCL: SV factor score thorough psychosocial risk factors, controlling for age of offspring at assessment

\begin{tabular}{|c|c|c|}
\hline $\begin{array}{l}\text { G3 females (daughters } \\
n=235 \text {, fathers } n=160 \text { ) }\end{array}$ & $\begin{array}{c}\text { Product of } \\
\text { coefficients, } \\
b \text { (s.e.) }\end{array}$ & $\begin{array}{c}\text { Bootstrapping, } \\
\text { BCa } \\
95 \% \mathrm{Cl}^{\mathrm{a}}\end{array}$ \\
\hline \multicolumn{3}{|l|}{$\begin{array}{l}\text { Factor } 1 \\
\text { Indirect effect }\end{array}$} \\
\hline Employment problems & $0.048(0.021)$ & \multirow{5}{*}{$\begin{array}{l}(0.008 \text { to } 0.132) \\
(-0.020 \text { to } 0.210)\end{array}$} \\
\hline Direct effect & $0.095(0.059)$ & \\
\hline Proportion of total effect mediated & 0.333 & \\
\hline Ratio of indirect to direct effect & 0.500 & \\
\hline Ratio of total to direct effect & 1.500 & \\
\hline \multicolumn{3}{|l|}{$\begin{array}{l}\text { Factor } 2 \\
\text { Indirect effect }\end{array}$} \\
\hline Employment problems & $0.033(0.014)$ & \multirow{5}{*}{$\begin{array}{l}(0.007 \text { to } 0.097) \\
(0.084 \text { to } 0.234)\end{array}$} \\
\hline Direct effect & $0.159^{* * *}(0.038)$ & \\
\hline Proportion of total effect mediated & 0.172 & \\
\hline Ratio of indirect to direct effect & 0.208 & \\
\hline Ratio of total to direct effect & 1.208 & \\
\hline $\begin{array}{l}\text { G3, generation three. } \\
\text { a. BCa, bias corrected and accelerated: } 5 \\
\star{ }^{\prime} P<0.05, * * P<0.01 \text {, } * \star * P<0.001 .\end{array}$ & bootstrap samples. & \\
\hline
\end{tabular}

problems and drug use. All three indirect effects are significant, but the direct effect is not. The indirect effect through accommodation problems is quite small $(b=0.037)$, and the indirect effects through employment problems $(b=0.068)$ and drug use are somewhat larger $(b=0.098)$. The total indirect effect $(b=0.202)$ is twice the size of the direct effect $(b=0.101)$. The proportion of the total effect that is mediated is 0.666 .

The results for female offspring (Table 5) show that the effect of the fathers' Factor 1 score on their female offspring's Factor 1 score is again mediated though the fathers' employment problems. However, only the indirect effect is significant $(b=0.048)$, and it is somewhat smaller than the direct effect $(b=0.095)$. The proportion of the total effect that is mediated is 0.333 . Finally, the effect of the fathers' Factor 2 score on the daughter's Factor 2 score is mediated once again, through the fathers' employment problems. Bootstrap results reveal that both direct and indirect effects are significant, with the size of the indirect effect $(b=0.033)$ being very small, compared with the direct effect $(b=0.159)$, with the proportion of the total effect mediated being 0.172 .

\section{Discussion}

\section{Main findings}

Intergenerational pathways for criminal and antisocial behaviour have been demonstrated by several empirical studies, but this is not the case for psychopathic personality traits, which are often found in violent and persistently antisocial individuals. The results from this study provide the first evidence that the psychopathic personality traits of a community sample of men have a significant association with the psychopathic personality traits of their male and female offspring.

Most significantly, this study suggests that the fathers' employment problems play an important role in explaining the intergenerational transmission of psychopathic personality traits (Factor 1 scores) to both male and female offspring. Previous analyses of CSDD data ${ }^{33}$ demonstrated that the psychopathic traits of the G2 males were not an asset in achieving life success. Other studies have shown that a fathers' occupational status had a significant positive relationship with emotionally detached (high score Factor 1, low score Factor 2) prisoners ${ }^{34}$ and in a third study, Lynam et $a l^{35}$ found that the socioeconomic status of the family (based on parental education and occupation) interacted with psychopathy in early adolescence to predict adult psychopathy scores. The transmission of the fathers' Factor 2 scores was also mediated by accommodation problems and drug use. This could be because of inconsistent parenting as a result of drug dependence.

Taken together, these findings are suggestive of several mechanisms that could be underlying the intergenerational transmission of psychopathic personality traits. A recent study found that subclinical psychopathy was related to counterproductive work behaviours ${ }^{36}$ and it could be the case that fathers with psychopathic traits and chronic employment problems spend more time in the family home, which has a negative impact on their offspring, as other studies have found. ${ }^{37}$ it is likely that these families would also experience financial hardship, social deprivation and parental conflict, which could contribute to childhood maltreatment and neglect, and these hypotheses certainly require further exploration.

\section{Limitations}

The study has several limitations that should be mentioned briefly; first, the Psychopathy Checklist has been subject to much debate, ${ }^{38,39}$ particularly because of its over- and underinclusivity of items for measuring the psychopathy construct, and interpretation of these results should bear these criticisms in mind. Second, we relied on the offspring's retrospective report of parenting, and there exists the possibility of recall bias. Third, this analysis treats intergenerational relationships as a unidirectional process, whereas there is increasing evidence for bidirectional processes. ${ }^{40,41}$ Future intergenerational studies should also take into account the influence of the characteristics of the child on the parent.

\section{Implications}

Despite these limitations, to the best of our knowledge, no prior studies have examined the familial nature of psychopathy 
prospectively in two consecutive generations using a measure that is known to be reliable and valid. This is also the first study to demonstrate mediation of the intergenerational relationship via psychosocial risk factors and further replication of these findings using different samples and alternative measures of the psychopathy construct are needed. Most importantly, the identification of specific risk factors that can partly explain intergenerational associations can provide important information for policymakers and practitioners by highlighting those who are particularly at risk, in the hope that resources could be more effectively focused on specific areas for intervention (i.e. particularly targeting families with histories of unemployment and substance misuse problems), as findings from this study and others suggest that high heritability does not equal immutability.

Our findings suggest several possibilities; first, this study found that certain psychosocial risk factors could explain the relationship between the psychopathy of fathers and their offspring. However, second, the association could also be explained by environmental risk factors that both generations are exposed to. Also, third, unmeasured genetic factors could account for the majority of intergenerational transmission. Finally, it is most likely that both genetic and environmental factors explain the development of psychopathic personality features in childhood and adolescence and their persistence into adulthood. Behavioural genetics studies have found that although genetic and environmental factors are equally responsible, the expression of a particular gene may vary according to the presence of other genes, as well as environmental factors, which themselves may be able to alter the way genes are expressed. It is also thought that non-shared environmental factors are responsible for variation in psychopathic traits from childhood through to adulthood. ${ }^{42}$ Further analyses of data from prospective longitudinal studies are crucial to test these intergenerational hypotheses. Further knowledge of the role of psychosocial risk factors in the aetiology of psychopathy has the potential to facilitate far more effective risk-focused prevention in the future.

Katherine M. Auty, PhD, David P. Farrington, PhD, Institute of Criminology, Cambridge University, Cambridge; Jeremy W. Coid, MD, Violence Prevention Research Unit, Barts and the London School of Medicine and Dentistry, Queen Mary College, University of London, London

Correspondence: Katherine Auty, Institute of Criminology, Cambridge University, Sidgwick Avenue, Cambridge CB3 9DA, UK. Email: ka404@cam.ac.uk First received 4 May 2014, final revision 30 Jun 2014, accepted 10 Jul 2014

\section{Funding}

This research was made possible by grants from the Home Office, the Department of Health, the Department of Education, the Raine Foundation, the Barrow Cadbury Trust and the Smith Richardson Foundation.

\section{Acknowledgements}

The authors wish to thank all the families involved in the CSDD and comments from two anonymous reviewers.

\section{References}

1 Smith CA, Farrington DP. Continuities in antisocial behavior and parenting across three generations. J Child Psychol Psychiatry 2004; 45: 230-47.

2 Thornberry TP, Freeman-Gallant A, Lizotte AJ, Krohn MD, Smith CA. Linked lives: the intergenerational transmission of antisocial behavior. J Abnorm Child Psychol 2003; 31: 171-84.

3 Hicks BM, Krueger RF, lacono WG, McGue M, Patrick CJ. Family transmission and heritability of externalizing disorders: a twin-family study. Arch Gen Psychiatry 2004; 61: 922-8.
4 Larsson $\mathrm{H}$, Andershed $\mathrm{H}$, Lichtenstein P. A genetic factor explains most of the variation in the psychopathic personality. J Abnorm Child Psychol 2006; 115: 221-30.

5 Viding E, Blair RJ, Moffitt TE, Plomin R. Evidence for substantial genetic risk for psychopathy in 7-year-olds. J Child Psychol Psychiatry 2005; 46: 592-7.

6 Lynam DR, Caspi A, Moffitt TE, Loeber R, Stouthamer-Loeber M. Longitudinal evidence that psychopathy scores in early adolescence predict adult psychopathy. J Abnorm Child Psychol 2007; 116: 155-65.

7 Farrington DP, Ullrich S, Salekin RT. Environmental influences on child and adolescent psychopathy. In Handbook of Child and Adolescent Psychopathy (eds RT Salekin and DR Lynam): 202-30. Guilford, 2010.

8 Gregory S, Ffytche D, Simmons A, Kumari V, Howard M, Hodgins S, et al. The antisocial brain: psychopathy matters: a structural MRI investigation of antisocial male violent offenders. Arch Gen Psychiatry 2012; 69: 962-72.

9 Lorber MF. Psychophysiology of aggression, psychopathy, and conduct problems: a meta-analysis. Psychol Bull 2004; 130: 531-52.

10 Raine A, Lee L, Yang Y, Colletti P. Neurodevelopmental marker for limbic maldevelopment in antisocial personality disorder and psychopathy. Br J Psychiatry 2010; 197: 186-92.

11 Yang $Y$, Raine A, Joshi AA, Joshi S, Chang YT, Schug RA, et al. Frontal information flow and connectivity in psychopathy. Br J Psychiatry 2012; 201: 408-9.

12 Loney BR, Huntenburg A, Counts-Allan C, Schmeelk KM. A preliminary examination of the intergenerational continuity of maternal psychopathic features. Aggress Behav 2007; 33: 14-25.

13 Connell AM, Goodman SH. The association between psychopathology in fathers versus mothers and children's internalizing and externalizing behavior problems: a meta-analysis. Psychol Bull 2002; 128: 746-73.

14 Moffitt TE, Caspi A, Rutter M, Silva PA. Sex Differences in Antisocial Behaviour: Conduct Disorder, Delinquency, and Violence in the Dunedin Longitudinal Study. Cambridge University Press, 2001.

15 LeBreton JM, Binnings JF, Adorno AJ. Sublinical psychopaths. In Comprehensive Handbook of Personality and Psychopathology, Personality and Everyday Functioning (eds JC Thomas, DL Segal and M. Hersen): 388-411. Wiley, 2006.

16 van Honk J, Hermans EJ, Putman P, Montagne B, Schutter DJ Defective somatic markers in sub-clinical psychopathy. Neuroreport 2002; 13 $1025-7$.

17 Hare RD, Neumann CS. Psychopathy as a clinical and empirical construct. Ann Rev Clin Psychol 2008; 4: 217-46.

18 Frick PJ, Bodin SD, Barry CT. Psychopathic traits and conduct problems in community and clinic-referred samples of children: further development of the Psychopathy Screening Device. Psychol Assess 2000; 12: 382-93.

19 Widom CS. A methodology for studying noninstitutionalized psychopaths J Consult Clin Psychol 1977; 45: 674-83.

20 Farrington DP. Key results from the first 40 years of the Cambridge Study in Delinquent Development. In Taking Stock of Delinquency: An Overview of Findings from Contemporary Longitudinal Studies (eds TP Thornberry and MD Krohn): 137-83. Kluwer/Plenum, 2003.

21 Hart SD, Cox DJ, Hare RD. Manual for the Psychopathy Checklist: Screening Version (PCL:SV). Multi-Health Systems, 1995.

22 Hare RD. Manual of the Psychopathy Checklist-Revised (2nd edn). MultiHealth Systems, 2003.

23 Acheson SK. Review of the Hare Psychopathy Checklist-Revised. In The Sixteenth Mental Measurements Yearbook (eds RA Spies and BS Plake): 429-31. Buros Institute of Mental Measurements, 2005.

24 Farrington DP, Coid JW, Harnett LM, Jolliffe D, Soteriou N, Turner RE, et al. Criminal Careers Up To Age 50 and Life Success Up To Age 48: New Findings from the Cambridge Study in Delinquent Development (Research Study No. 299). Home Office, 2006

25 Ewing JA. Detecting alcoholism. JAMA 1984; 252: 1905-7.

26 West DJ, Farrington DP. Who Becomes Delinquent? Heinemann, 1973.

27 Farrington DP. Psychosocial predictors of adult antisocial personality and adult convictions. Behav Sci Law 2000; 18: 605-22.

28 Farrington DP. Family background and psychopathy. In Handbook of Psychopathy (ed CJ Patrick): 229-50. Guilford Press, 2006.

29 Baron RM, Kenny DA. The moderator-mediator variable distinction in social psychological research: conceptual, strategic, and statistical considerations. J Pers Soc Psychol 1986; 51: 1173-82.

30 MacKinnon DP, Fairchild AJ, Fritz MS. Mediation analysis. Ann Rev Psychol 2007; 58: 593-614.

31 Mackinnon DP. Multiple mediator model. In Introduction to Statistical Mediation Analysis: 103-25. Lawrence Erlbaum Associates, 2008. 
32 Cohen P. Childhood risks for young adult symptoms of personality disorder: method and substance. Multivariate Behav Res 1996; 31: 121-48.

33 Ullrich S, Farrington DP, Coid JW. Psychopathic personality traits and lifesuccess. Pers Individ Dif 2008; 44: 1162-71.

34 Patrick CJ, Zempolich KA, Levenston GK. Emotionality and violent behavior in psychopaths: a biosocial analysis. In Biosocial Bases of Violence (eds A Raine, A Brennan, DP Farrington and SA Mednick): 145-61. Plenum Press, 1997

35 Lynam DR, Loeber R, Stouthamer-Loeber M. The stability of psychopathy from adolescence into adulthood: the search for moderators. Crim Justice Behav 2008; 35: 228-43.

36 Scherer KT, Baysinger M, Zolynsky D, LeBreton JM. Predicting counterproductive work behaviors with sub-clinical psychopathy: beyond the five factor model of personality. Pers Individ Dif 2013; 55: 300-5.

37 Jaffee SR, Moffitt TE, Caspi A, Taylor A. Life with (or without) father: the benefits of living with two biological parents depend on the father's antisocial behavior. Child Dev 2003; 74: 109-26.
38 Skeem JL, Cooke DJ. Is criminal behavior a central component of psychopathy? Conceptual directions for resolving the debate. Psychol Assess 2010; 22: 433-45.

39 Hare RD, Neumann CS. The role of antisociality in the psychopathy construct: comment on Skeem and Cooke (2010). Psychol Assess 2010; 22: 446-54.

40 Hawes DJ, Dadds MR, Frost AD, Hasking PA. Do childhood callousunemotional traits drive change in parenting practices? J Clin Child Adolesc Psychol 2011; 40: 507-18.

41 Pardini DA. Novel insights into longstanding theories of bidirectional parent-child influences: introduction to the special section. $J$ Abnorm Child Psychol 2008; 36: 627-31.

42 Raine A, Glenn AL. Psychopathy: An Introduction to Biological Findings and Their Implications. New York University Press, 2014.

\section{Biological psychiatry}

\section{Philip Cowen}

Guze's famous essay on biological psychiatry - 'Is there any other kind?' - argued that humans are biologically evolved creatures, therefore biological processes must contribute importantly to psychiatric disorder. True enough, though perhaps it was inevitable that 'biological' psychiatry would be defined in opposition to other kinds of psychiatry like 'psychosocial', which would then return to depict it as mindless, blind to context and medically hegemonic. Pluralism is a great relief. Biological processes are always involved, and we can try to utilise them for understanding and treatment if it helps - but we don't have to. Biopsychosocial psychiatry - is there any other kind? 